10

11

5

\section{A Modest Proposal for Restoration Ecology}

Cameron Brick, $\mathrm{PhD}$

Department of Psychology

University of Cambridge, UK

Published in Restoration Ecology, 2019

doi.org/10.1111/rec.12943
Corresponding author: Cameron Brick, brickc@gmail.com, Department of Psychology, University of Cambridge, Downing Street, Cambridge, United Kingdom CB2 3EB

Author Contributions: CB conceived of, wrote, and edited the manuscript. 
Abstract

Restoration ecology struggles to mitigate human-caused ecological damage. Non-native species are a particular challenge. This article describes two restoration attempts following introduced species in California and then makes a radical culling proposal. Environmental regulations, legal protections, and restoration projects are necessary to preserve ecosystem services, but such policies are often unpopular. Restorers often struggle when public opinion opposes evidence-based practice, and this occurs particularly when the interventions involve killing mammals. Therefore, restoration efforts may benefit from more attention to how individuals perceive the acceptability of environmental policies and how to communicate policy options effectively for individuals to make informed decisions. Restoration ecology can follow the recent shift of medicine away from imperatives and towards informed patient choice. Restoration projects may benefit from recent advances in psychology and communication that help individuals make policy decisions that align with their personal values.

Conceptual Implications

- Current restoration methods are insufficient to cope with human-caused damage.

- Unpopular interventions will be become more necessary for restoration ecology, driving a need for more effective communication with stakeholders.

- A radical cull is suggested for key injurious species.

- Restoration ecology can follow the recent shift in medicine away from imperatives and towards informed stakeholder choice. \\ Keywords}

non-native species; policy; psychology; decision making; human geography; Anthropocene 
"Show me a hero and I will write you a tragedy." -- F. Scott Fitzgerald

Restoration ecology struggles with the pace and depth of human-caused ecosystem damage. One recurring challenge is non-native species introduced through human activity. When non-native plant and animal species become established, they often displace native species and decrease biodiversity, which lowers ecosystem stability (Pyšek et al. 2012). Non-native species can have neutral or even positive impacts on ecosystems (Lampert et al. 2014), but many ecosystem effects are swift and negative. Restoration ecology can intervene to help stabilize key populations of plants and animals and preserve ecosystem services, but it is even difficult to identify the best target species (Kumschick et al. 2012; Jeschke et al. 2014) let alone successfully intervene. Worse, many interventions lead to unforeseen problems such as reduced biodiversity. Against the challenge of global environmental damage, the successes of restoration ecology are modest. There is a need for ambitious stretch goals to spur developments in restoration practice (Manning et al. 2006; Aronson \& Alexander 2013), especially because prevention is the most effective strategy (Waage \& Reaser 2001). This manuscript presents a controversial stretch goal based on further integrating human factors into restoration (Cairns et al. 2012). Below, two restoration attempts following introduced species in California are used as examples and then a radical intervention is suggested.

\section{Restoration Attempts}

The South African ice plant (Carpobrotus edulis) was deliberately planted in California to stabilize the ground near railroad tracks (D'Antonio 1990). However, C. edulis thrived and spread, establishing vast carpets across ecosystems, including the sensitive coastal areas of foredune, dune scrub, coastal bluff scrub, coastal prairie, and maritime chaparral. An ironic twist is that it worsens erosion due to shallow roots and large biomass and crowds out native species (D'Antonio 1990). To date, there are no biological methods to control ice plant, and chemical and mechanical eradication are expensive and damage other plants. National, state, and even local citizen groups (Pascoe 2012) valiantly remove ice plant in priority areas, but eradication from California is effectively impossible.

A second management example serves to illustrate the importance of public opinion. Feral pig descendants of Sus scrofa were raised commercially on Santa Cruz Island from the $1850 \mathrm{~s}$ and then escaped to the wild. Their relentless digging facilitated the proliferation of non-natives such as fennel (Foeniculum vulgare), which quickly spread across the island and crowded out native flora. The presence of the pigs also attracted golden eagles (Aquila chrysaetos), who in turn decimated the island fox (Urocyon littoralis) population to below 100 individuals (Menard 2005). The severity of this near-extinction event may have been an advantage to the public debate around restoration methods. When non-native species threaten extinctions or destabilize entire ecosystems, aggressive policy solutions may become more acceptable. The scientific community recommended complete pig eradication on Santa Cruz Island, but there was still widespread public resistance. Years of public debate, community discussion, and open dialog led to a narrow consensus for eradication using trapping, poisoning, and even shooting from helicopters. The campaign was an striking success: the conservation status of $U$. littoralis improved to Near Threatened (IUCN 3.1; (Milman 2016; Coonan et al. 2013) and the public resistance waned over time.

When non-native species become well-established in an ecosystem, they are often prohibitively difficult to eradicate (Waage \& Reaser 2001). Preventative interventions can be cheaper and more effective. Both C. edulis and S. scrofa arrived through the vector of a 
single Hominidae mammal, itself an established non-native in North America transported overland from Asia during the Pleistocene. The ecological impact of this creature exceeds all other current species. It may have caused a new geologic age, the Anthropocene, based on dramatic changes to land, sea, air, and the climate (IPCC 2013; Dietz et al. 2007). Because there are no remaining ecosystems unaffected by this creature, effective ecological restoration in the 21 st century might be improved by intervening more directly.

\section{A Modest Proposal}

Despite optimistic reports that local communities can solve collective action problems (Ostrom 1990/2011), the current effectiveness of restoration ecology is not commensurate to its global challenges. The radical suggestion for restoration ecology is a managed population reduction of Homo sapiens and restriction in its range. Wildlife managers could employ a combination of mechanical, biological, and chemical methods. To support the efforts and expense, the managed reduction can be made legally robust. In the United States, the Lacey Act is a conservation law that regulates the movement of wildlife, fish, and plants. The Lacey Act could be used to label $H$. sapiens an 'injurious species' based on its unprecedented negative impacts, and this would facilitate policies limiting its future harm. Any proposals to cull charismatic megafauna such as $H$. sapiens risk unpopularity, but wildlife managers may need to consider even unpopular ideas for even a chance of maintaining current biodiversity and acceptably stable ecosystems. Unmanaged $H$. sapiens appears likely to savage global ecosystems within the next century, particularly through climate change.

Recently, a satirical proposal to reforest all of Spain as a wilderness generated more attention than a contemporary risk analysis on the same topic that contained typical caveats. The provocateurs wrote: "Satire can help reveal the flaws inherent in the way we frame, formulate, and impose our views on different situations" (Meijaard \& Sheil 2011, pp. 525; also see Bore \& Reid 2014). Jonathan Swift wrote A Modest Proposal in 1729, a tongue-incheek argument for the numerous benefits to broader society of eating babies: "I shall now therefore humbly propose my own thoughts, which I hope will not be liable to the least objection." The culling proposal is intended as transparent satire. The goal is to constructively illuminate weaknesses in current restoration policy and perhaps stimulate openness to new methods.

\section{A Way Forward}

Current restoration attempts are incommensurate with the scope of global damage, in part because of gaps between brave ideas, public opinion, and public policy. Restoration policy is often unpopular when it limits economic activity or recreation. Wildlife managers also struggle to shift public opinion in favor of restoration when the interventions involve killing mammals such $S$. scrofa. Scientists and environmental interest groups sometimes respond by designing persuasive messages, but these risk paternalism and stoking partisan conflict between perceived social groups (i.e., environmentalists and farmers). Changing beliefs or behaviors requires effective persuasion, for example on how people perceive the acceptability of environmental policies (Diepeveen et al. 2013).

I propose that restoration efforts might benefit from more attention to the social science on communication. When local stakeholders understand the expected harms and benefits of different policies, they are more able to select restoration policies that match their goals and values (Brick et al. 2018). This approach to shared decision making may help preserve not only native species and biodiversity but also a thriving future for humans. Achieving shared governance with procedural justice requires communicating policy 
options in balanced and honest ways that help people make informed decisions. A recent review of how policies are communicated suggests that stakeholders frequently lack key information and communicators lack effective strategies for helping others reach decisions (Brick et al. 2018).

A recent pivot in medicine offers another useful shift in perspective. Ecological restorers do healing work similar to how doctors treat patients (Throop \& Purdom 2006). decisions are presented to patients. There is a recent shift away from expert control and towards informed patient choice. Doctors make more ethical decisions when they incorporate the values and goals of the patient in the decision making process. Restoration and conservation practitioners can also move away from imperatives and towards informed stakeholder choice. Indeed, this shift is already occurring. Recently, human involvement in restoration projects (e.g., volunteering) is seen as more central than was previously recognized. Participation in restoration can help integrate humans into the ecosystem in ways that benefit both people and nature (Throop \& Purdom 2006). "[S]ocial engagement is a vital part of restoration, not merely an afterthought... restoration must be conceived in a way that makes the connections between culture and ecology, people and place, prominent." (Higgs 2003, pp .257).

As suggested recently (Martin 2017), restoration ecology may earn more public support when restoration efforts are explained and justified through human values. The benefits of well-functioning ecosystems can be described through ecosystem services and more abstract values such as fairness (e.g., whether we provide space for other species to exist). This requires understanding how people perceive risk and how to communicate effectively. As wilderness decreases and human developments expand, restoration projects are likely to come into more conflict with human settlements. A robust integration of human factors with the entire timeline of restoration (Cairns et al. 2012) could support more productive debates. The $S$. scrofa example above was a demonstration of success, but it was only achieved after difficult, sincere, and repeated engagement with local stakeholders. The C. edulis example also shows the importance of engaging the public: much of the current, valuable work in sensitive and degraded ecosystems is being initiated, led, and completed by non-specialist volunteers (Pascoe 2012).

A managed cull of $H$. sapiens would be profoundly immoral and ineffective and is offered here only as a rhetorical device to show the disconnect between current restoration goals and practice. Instead, I advocate a renewed interest in the psychology of communication and decision making. Effective communication could lead to greater public acceptability for restoration projects, for example by highlighting how project goals align with the existing values of the human audience. The alternative is to hope that people will find and use the right evidence and make appropriate long-term decisions. However, there is no time to spare. As ecosystems become more degraded and fragile through human development and climate change, the remaining ecosystem restoration options may become even harder to justify to a public coping with both adaptation and mitigation challenges.

\section{Acknowledgements}

Thanks to Adam McLain whose misanthropic tendencies helped inspire this idea during a hike in the Adirondacks, and thanks to the reviewers who improved the argument and constructive balance of satire and sincerity. This research did not receive any specific grant 
from funding agencies in the public, commercial, or not-for-profit sectors.

\section{References}

Aronson J, Alexander S (2013) Ecosystem restoration is now a global priority: Time to roll up our sleeves. Restoration Ecology 21:293-296

Bore I-LK, Reid G (2014) Laughing in the face of climate change? Satire as a device for engaging audiences in public debate. Science Communication 36:454-478

Brick C, Freeman ALJ, Wooding S, Skylark WJ, Marteau T, Spiegelhalter DJ (2018) Winners and losers: communicating the potential impacts of policies. Palgrave Communications 4:69

Coonan T, Ralls K, Hudgens B, Cypher B, Boser C (2013) Urocyon littoralis. The IUCN Red List of Threatened Species (Version 2014.1.)

D'Antonio CM (1990) Seed production and dispersal in the non-native, invasive succulent Carpobrotus edulis (Aizoaceae) in coastal strand communities of Central California. Journal of Applied Ecology 27:693-702

Diepeveen S, Ling T, Suhrcke M, Roland M, Marteau TM (2013) Public acceptability of government intervention to change health-related behaviours: a systematic review and narrative synthesis. BMC Public Health 13:756

Dietz T, Rosa EA, York R (2007) Driving the human ecological footprint. Frontiers in Ecology and the Environment 5:13-18

Higgs E (2003) Nature by design: People, natural process, and ecological restoration. MIT Press

IPCC (2013) AR5 synthesis report. Intergovernmental Panel on Climate Change

Jeschke JM, Bacher S, Blackburn TM, Dick JTA, Essl F, Evans T et al. (2014) Defining the impact of non-native species: Impact of non-native species. Conservation Biology 28:1188-1194

Cairns S, Dudley N, Hall C, Keeneleyside K, Stolton S (2012) Ecological restoration for protected areas: Principles, guidelines and best practices. IUCN

Kumschick S, Bacher S, Dawson W, Heikkilä J, Sendek A, Pluess T, Robinson TB, Kühn I (2012) A conceptual framework for prioritization of invasive alien species for management according to their impact. Working paper series 15:69-100

Lampert A, Hastings A, Grosholz ED, Jardine SL, Sanchirico JN (2014) Optimal approaches for balancing invasive species eradication and endangered species management. Science 344:1028-1031

Manning AD, Lindenmayer DB, Fischer J (2006) Stretch goals and backcasting: Approaches for overcoming barriers to large-scale ecological restoration. Restoration Ecology 14:487-492

Martin DM (2017) Ecological restoration should be redefined for the twenty-first century. Restoration Ecology 25:668-673

Meijaard E, Sheil D (2011) A modest proposal for wealthy countries to reforest their land for the common good. Biotropica 43:524-528

Menard Y (2005) Feral pig eradication begins on Santa Cruz Island. Channel Islands National Park (U.S. National Park Service). https://www.nps.gov/chis/learn/news/feralpig-eradication-begins-on-santa-cruz-island.htm (accessed 18 June 2018).

Milman O (2016) Rare island fox taken off endangered list after record-breaking recovery. The Guardian. http://www.theguardian.com/world/2016/aug/12/rare-island-fox- 
removed-endangered-species-list-california (accessed 18 June 2018).

Ostrom E (1990/2011) Governing the Commons: The Evolution of Institutions for Collective Action. Cambridge University Press, Cambridge, United Kingdom

Pascoe J (2012) Restoring native beauty and diversity along West Cliff Drive. The Santa Cruz Sentinel. http://www.santacruzsentinel.com/article/zz/20120706/NEWS/120707945 (accessed 18 June 2018).

Pyšek P, Jarošík V, Hulme PE, Pergl J, Hejda M, Schaffner U, Vilà M (2012) A global assessment of invasive plant impacts on resident species, communities and ecosystems: the interaction of impact measures, invading species' traits and environment. Global Change Biology 18:1725-1737

Throop W, Purdom R (2006) Wilderness restoration: The paradox of public participation. Restoration Ecology 14:493-499

Waage JK, Reaser JK (2001) A global strategy to defeat invasive species. Science 292:1486-1486 